\title{
Short- and long-term outcome of patients aged 65 and over after cardiac surgery
}

\author{
STJEPAN BARISIN ${ }^{1,7}$, DANIJEL UNIC 2 , HELENA OSTOVIC ${ }^{1,7}$, MIROSLAV ZUPCIC ${ }^{3}$, \\ TONCI BOZIN", VIKTOR DUZEL ${ }^{5}$, ANA BARISIN ${ }^{6}$, JURE MIRAT 7 \\ 1 Clinical Department of Anesthesiology, Reanimatology and Intensive Care, Referral Centre of the Ministry of Health for \\ Hemodynamic Monitoring in Intensive Care of Surgical Patients, Dubrava University Hospital, Zagreb, Croatia; \\ 2 Department of Cardiac Surgery and Transplantation, University Department of Surgery, Dubrava University Hospital, Zagreb; \\ 3 Clinical Department of Anesthesiology, Reanimatology and Intensive Care, Clinical Hospital Center Rijeka; \\ 4 University Department of Medicine, Dubrava University Hospital, Zagreb; \\ 5 Department of Anaesthesia, Barking, Havering and Redbridge University Hospitals NHS Trust, London, United Kingdom; \\ 6 Department of Medicine, Medikol Polyclinic, Zagreb; \\ 7 Faculty of Medicine, University J.J. Strossmayer Osijek, Osijek.
}

Address of corresponding author:

Stjepan Barisin. MD, PhD

Department of Cardiac Anesthesia and Intensive Care, Clinical Department of Anesthesiology, Reanimatology and Intensive

Care, Referral Centre of the Ministry of Health for Hemodynamic Monitoring in Intensive Care of Surgical Patients,

Dubrava University Hospital, Av. Gojka Suska 6, 10000 ZAGREB, Croatia

Telephone: +385-(0)1-290-28-30 E-mail adress: sbarisin@gmail.com

\section{ABSTRACT}

To analyze the short and long-term outcome of patients aged 65 years and over, after cardiac surgery. Over a 12-year period we analyzed 1750 patients with a mean age of $70.09 \otimes 3.94$ years. They were classified into three age groups: between 65 and 69 $(\mathrm{n}=709)$, between 70 and $74(\mathrm{n}=695)$ and 75 years and above $(n=346)$. Followup information was obtained by telephone conversation after a 6-month and 3-year period of discharge from the hospital. Included in the follow-up were 1235 patients and an interview was conducted with 501 (40.6\%) patients or their next of kin.

Even though the in-hospital morbidity was highest in the oldest age group, there were no significant differences between groups $(\mathrm{p}=0.051)$. There was no significant difference between groups in the length of hospital stay. The greatest in-hospital mortality was noted in the oldest age group ( $\mathrm{p}$ $=0.046$ ) compared to patients in the age groups between 65 and 69 and between 70 and 74 years old $(\mathrm{p}=0.023$ and $\mathrm{p}=$ 0.036). In the follow-up study, there was a significantly smaller telephone feedback response in the oldest age group compared to the youngest group ( $\mathrm{p}=0.003)$. There were no differences between the groups with respect to mortality and cardiac death after the 6-month and 3-year periods of discharge from hospital.

Our data showed that despite a poor short - and long-term outcome in patients aged 75 and over, all patients had an acceptable operative risk.
Keywords: elderly; outcome; cardiac surgery

\section{INTRODUCTION}

According to the Croatian Bureau of Statistics, in the year 2011 there were 4284 889 citizens in Croatia with a portion of those aged 65 and over at $17.7 \%$ (in 2001 it was at 15.7\%) (1). Furthermore, in 2016 there were 4154213 citizens in Croatia with a portion of those aged 65 and over increased at $19.6 \%$ (2).

From the statistics above, it can be seen that the Croatian population is rapidly aging and is marked by a significantly advanced age. The age index derived from the number of citizens aged 65 years and above in comparison to the age group of $0-14$ years of age was 116.3 (in 2001 it was 91.9), which means that for the first time in the history of Croatia, in 2011 there were more senior citizens than those of a younger age $(1,3)$.

Longer life expectancy has lead to increased incidence of cardiovascular disease, the primary cause of morbidity and mortality in the elderly. This represents a special challenge for cardiac surgery in the population above 65 years of age. Commonly, cardiac surgery in the elderly is associated with a higher risk of death and longer hospital stay which leads many patients to question the feasibility of such procedures. Contrary to this, advances in anesthetic and surgical techniques, as well as improved perioperative care, have resulted in a significant improvement in short and long-term outcomes after open heart surgery in the elderly $(4,5)$.

The purpose of this study was to determine the short-term clinical outcome (in-hospital mortality and morbidity) in patients who underwent elective cardiac surgery and were aged 65 years and above. Followup information about their long-term outcome was obtained from telephone conversations after a 6-month and 3-year period of discharge from the hospital.

\section{PATIENTS AND METHODS}

Over a 12-year period (between January 1998 and December 2009) patients aged 65 years and above, who underwent elective coronary and valve open-heart surgery were included in this retrospective observational study. The computerized database "CardioBase" of the Department of Cardiac Surgery and Transplantation at University Hospital Dubrava Zagreb, was used to identify 1750 consecutive patients. All other types of cardiac surgery, except coronary and valve surgery, were not included in the study such as urgent surgery and revision. The study was compiled in accordance with the Declaration of Helsinki. No specific written conset was acquired for this study since all cardiac surgical patients' data were anonymous.

All patients received standard premedication with morphine in dose of $0.1 \mathrm{mg} /$ kg IM (Morphine Merck $^{\circledast}$, Merck KgaA, Darmstadt, Germany) and other of their cardiac medications one hour before sur- 
gery. Anesthesia induced with midazolam (Dormicum ${ }^{\oplus}$, F. Hoffman-La Roche Ltd., Basel, Switzerland) $0.1 \mathrm{mg} / \mathrm{kg}$ IV, fentanyl (Fentanyl ${ }^{\circ}$ Janssen Pharmaceutica, Beerse, Belgium) $5-7 \mu \mathrm{g} / \mathrm{kg} \mathrm{IV}$, and pancuroniumbromide (Pavulon', N.V. Organon, Oss, the Netherlands) $0.1 \mathrm{mg} / \mathrm{kg}$ IV. After endotracheal intubation, the lungs were mechanically ventilated using positive pressure (tidal volume $8 \mathrm{~mL} / \mathrm{kg}$, ventilatory frequency $12 / \mathrm{min}$ ) (Cato, Dräger, Lübeck, Germany). Anesthesia was maintained with a nitrous-oxide mixture $(60 \%$ oxygen and $40 \%$ nitrous oxide) and sevoflurane (Sevorane $^{\oplus}$, Abbott Laboratories S.A., Abbott Park, IL, USA) in doses of 1-1.5 minimal alveolar concentration (MAC). ASA standard monitors were applied and arterial and venous catheters were inserted to measured pressures and cardiac output on admission to the operating room.

Moderate hypothermia $\left(32-34{ }^{\circ} \mathrm{C}\right)$ or normothermia was maintained during cardiopulmonary bypass (CBP - heparing-coated circuit) with composition of priming volume: infusol solution 1200 ml (Pliva, Zagreb, Croatia), mannitol 20\% $250 \mathrm{ml}$ (Croatian Institute of Transfusion Medicine, Zagreb, Croatia), human albumin 20\% $100 \mathrm{ml}$ (Institute of Immunology, Zagreb, Croatia) and heparin sodium 10,000 I.U. (Belupo, Koprivnica, Croatia). Myocardial perfusion during aortic cross clamping (ACC) was obtained by cold blood cardioplegia strategy (a modified Gerald Buckberg solution mixture was a 4:1 oxygenated blood to crystalloid ratio) to achieve cardiac arrest. Activated clotting time (ACT) was maintained greater than 480 seconds for CPB. Starting dose of heparin 300 units/kg was reversed with protamine sulfate (Fresenius Kabi, Lake Zurich, IL, USA) in a 1 to 1-1.5 ratio. The target mean arterial pressure was $60 \mathrm{mmHg}$ during CPB and $60-80 \mathrm{mmHg}$ after CPB. After surgery, patients were transferred to the ICU. Criteria for hospital discharge included hemodynamic and rhythm stability, an afebrile condition with the absence of surgical incision site infection and feeding. The patients were classified into three cohorts. The first group $(\mathrm{n}=709)$ was between 65 and 69 years old, the second group $(\mathrm{n}=695)$ was between 70 and 74 years old and the third group $(n=346)$ was aged 75 years and above. The mean age of patients, which included 1201 men and 549 women, was 70.09 \ 3.94 years (range 65 to 87 ). The mean logistic EuroSCORE of the 1750 patients was $5.42 \pm 2.49$ ( Table 1). The observed parameters were inhospital morbidity, mortality and length of hospital stay.

Follow-up was conducted through conversation either with the patient or the next of kin by telephone. It was related to the two observed periods: the 6-month and the 3-year period, of discharge from the hospital. A pre-planned questionnaire included the time and cause of death where warranted. The telephone conversations were carried out between March and October of 2017. In the case where there was no answer to the phone calls, a further two calls were made in the following three weeks. The follow-up study included 1750 patients and an interview was conducted with only $711(40.6 \%)$ patients or the next of kin by telephone.

For data analysis, the SAS System for Windows Release 9.4 software (SAS Institute Inc., Cary, NC, USA) was used. Numerical data were expressed as mean $\nabla$ the standard deviation. Quantitative variables were analyzed for the normality of distribution using the Kolmogorov-Smirnov test. Qualitative data were described by frequencies. To compare the three independent groups, categoric variables were analyzed using the two-tailed Pearson $\chi 2$ test. To compare the three independent groups, continuous variables which were not normally distributed were analyzed using the Kruskal-Wallis test. To find differences between the three groups, we tested the groups in pairs by the Mann-Whitney test corrected for multiple testing. All statistical values were considered significant at $\mathrm{p}<0.05$.

\section{RESULTS}

Preoperative and operative data of the study are shown in Table 1. Demographics and preoperative data were similar between three groups except for EuroScore where all three groups mutually significantly differ ( $p<0.001$ for all). Coronary artery bypass grafting (CABG) was performed in 1036 patients. Out of 1036 coronary patients, 476 patients (45.9\%)

Table 1. Preoperative and operative data

\begin{tabular}{|c|c|c|c|c|}
\hline \multirow[t]{2}{*}{ Variable } & \multicolumn{4}{|l|}{ Patients } \\
\hline & $\begin{array}{l}65-69 \text { years }(n=709) \\
\text { mean } \pm S D\end{array}$ & $\begin{array}{l}70-74 \text { years }(n=695) \\
\text { mean } \pm S D\end{array}$ & $\begin{array}{l}75 \text { and above }(n=346) \\
\text { mean } \pm \text { SD }\end{array}$ & P-value $\dagger$ \\
\hline \multicolumn{5}{|l|}{ Preoperative data } \\
\hline Sex $\quad M(n)$ & 507 & 469 & 225 & 0.073 \\
\hline $\mathrm{F}(\mathrm{n})$ & 202 & 226 & 121 & 0.253 \\
\hline Diabetes mellitus (n) & 116 & 120 & 46 & 0.252 \\
\hline Hypertension (n) & 311 & 285 & 134 & $0.412 \ddagger$ \\
\hline Ejection fraction (\%) & $56.96 \pm 11.65$ & $55.90 \pm 11.86$ & $56.19 \pm 11.65$ & $<0.001 \ddagger$ \\
\hline EuroSCORE & $4.64 \pm 2.33$ & $5.46 \pm 2.32$ & $6.66 \pm 2.42$ & \\
\hline \multicolumn{5}{|l|}{ Operative data } \\
\hline CABG/OPCABG (n) & $455 / 203$ & $395 / 186$ & $186 / 87$ & 0.002 \\
\hline Valve (n) & 153 & 180 & 93 & 0.183 \\
\hline Valve and CABG (n) & 101 & 120 & 67 & 0.087 \\
\hline $\mathrm{CPB}(\min )$ & $107.19 \pm 50.52$ & $110.97 \pm 48.70$ & $113.96 \pm 46.69$ & $0.026 \ddagger$ \\
\hline $\mathrm{ACCT}(\min )$ & $65.81 \pm 28.10$ & $67.97 \pm 31.03$ & $70.65 \pm 30.36$ & $0.095 \ddagger$ \\
\hline
\end{tabular}

Data expressed as mean and standard deviation (SD). CABG - coronary artery bypass grafting, OPCABG - coronary artery bypass grafting without cardiopulmonary bypass, $\mathrm{CPB}$ - cardiopulmonary bypass, ACCT - aortic cross clamp time.

†comparison between groups with Pearson $\chi 2$ test;

\$comparison between groups with Kruskal-Wallis test. 
Table 2. Short-term outcome (in-hospital mortality and morbidity)

\begin{tabular}{|c|c|c|c|c|}
\hline \multirow[t]{3}{*}{ Variable } & \multicolumn{4}{|l|}{ Patients } \\
\hline & $65-69$ years $(n=709)$ & $70-74$ years $(n=695)$ & 75 and above $(n=346)$ & P-value $\dagger$ \\
\hline & $\%$ & $\%$ & $\%$ & \\
\hline Morbidity (n) & $77(10.9)$ & $97(14.0)$ & $55(15.9)$ & 0.051 \\
\hline Prolonged MV (n) & $28(3.9)$ & $21(3.0)$ & $20(5.8)$ & 0.200 \\
\hline Perioperative MI (n)* & $17(2.4)$ & $17(2.4)$ & $14(4.0)$ & 0.372 \\
\hline $\operatorname{LCOS}(n)$ & $15(2.1)$ & $16(2.3)$ & $10(2.9)$ & 0.658 \\
\hline CVI (n) & $12(1.7)$ & $16(2.3)$ & $11(3.2)$ & 0.303 \\
\hline $\mathrm{AKI}(\mathrm{n})$ & $11(1.6)$ & $10(1.4)$ & $6(1.7)$ & 0.936 \\
\hline Sepsis (n) & $22(3.1)$ & $35(5.0)$ & $14(4.0)$ & 0.186 \\
\hline MODS (n) & $12(1.7)$ & $13(1.9)$ & $12(3.5)$ & 0.144 \\
\hline Length of stay (days) & $17.49 \pm 10.52$ & $18.12 \pm 10.78$ & $18.48 \pm 12.30$ & 0.418 \\
\hline Hospital mortality (n) & $39(5.5)$ & $40(5.8)$ & $32(9.2)$ & $0.046 \ddagger$ \\
\hline
\end{tabular}

Data expressed as percent (\%), mean and standard deviation (SD). MI* - myocardial infarction include patients undergoing coronary and valvular surgery, MV - mechanical ventilation, LCOS - low cardiac output syndrome, CVI - cerebrovascular insult or stroke, MODS - multiple organ dysfunction syndrome, AKI - acute kidney injury.

†comparison between groups with Pearson $\chi 2$ test;

$\ddagger$ comparison between groups with Kruskal-Wallis test.

Table 3. Long-term outcome

\begin{tabular}{|c|c|c|c|c|}
\hline Variable & Patients & & & \\
\hline & $65-69$ years $(n=709)$ & $70-74$ years $(n=695)$ & 75 and above $(n=346)$ & P-value $\dagger$ \\
\hline & $\%$ & $\%$ & $\%$ & \\
\hline Response to telephone call (n)* & $328(46.2)$ & $270(38.8)$ & $103(29.7)$ & 0.001 \\
\hline \multicolumn{5}{|l|}{ Follow up to 6 months } \\
\hline Mortality (n) & $12(3.7)$ & $9(3.3)$ & $8(7.8)$ & 0.198 \\
\hline Cardiac death $(\mathrm{n})$ & $7(2.1)$ & $6(2.2)$ & $7(6.8)$ & 0.115 \\
\hline \multicolumn{5}{|l|}{ Follow up to 3 years } \\
\hline Mortality (n) & $32(9.8)$ & $30(11.1)$ & $15(14.6)$ & 0.545 \\
\hline Cardiac death (n) & $17(5.2)$ & $16(5.9)$ & $5(4.9)$ & 0.929 \\
\hline
\end{tabular}

†comparison between groups with Pearson $\chi 2$ test;

underwent coronary artery bypass grafting without cardiopulmonary bypass (OPCABG). Valve surgery was performed in 429 patients, and concomitant procedures of CABG and valve surgery in 287 patients. A significantly greater number of patients underwent coronary surgery in the youngest age group in comparison to the other two groups $(\mathrm{p}=0.007$ and $\mathrm{p}=0.001)$. The duration of $\mathrm{CPB}$ was significantly longer in the oldest age group compared to the youngest group $(\mathrm{p}=0.007)$. Although aortic cross clamp time was the longest in the oldest age group, there were no significant differences between groups (Table 1).

There were no significant differences between the groups in terms of prolonged mechanical ventilation, incidence of perioperative myocardial infarction, low cardiac output syndrome, stroke, acute kidney injury (AKI), sepsis and multiple organ dys- function syndrome. Even though hospital morbidity was greatest in the oldest age group, there were no significant differences between the groups $(\mathrm{p}=0.051)$. There was no significant difference between the groups in length of hospital stay. A significantly greater mortality was noted in the oldest age group compared to the other two groups $(\mathrm{p}=0.023$ and $\mathrm{p}=0.036)(\mathrm{Ta}$ ble 2).

In the follow-up study, a significantly smaller response to the phone interview was noted in the oldest group compared to the youngest age group $(\mathrm{p}=0.003)$. There were no differences between the groups with respect to mortality and cardiac death after the 6-month and the 3-year periods of discharge from the hospital (Table 3).

\section{DISCUSSION}

According to the Croatian Bureau of Statistics, from 2011 until today, there have been more senior citizens aged 65 years and above than those of a younger age $(1,2)$. Also, today's population in Europe is rapidly ageing. The need for cardiac surgery in elderly patients is rising and a growing number of cardiac patients are presented with coronary heart disease and degenerative valve disease. This is the first retrospective observational report assessing the results of elective cardiac surgery in patients aged 65 and above, categorized into three age groups. Over a 12 -year period, from the database, 1750 consecutive patients from 65 to 87 years of age were identified, with the mean age of patients being 70 . 
Older patients have different cardiac diseases, more comorbidities and are usually referred later for surgery (4). In our study, the youngest age group of patients, between 65 and 69 years old, more commonly suffered from hypertension, while patients between 70 and 74 years of age, more often suffered from diabetes mellitus. The logistic EuroSCORE was used to stratify patients, since it is known to be the most accurate predictor of death in high risk cases (6). It seems to overestimate mortality at lower score levels (EuroSCORE $\leq 6)$ and underestimate mortality at higher score levels (EuroSCORE > 13) (7). Sündermann et al. (8) report 30-day mortality of $5.5 \%$ in 400 cardiac surgical patients $\geq 74$ years with EuroSCORE 8.5, while in our the oldest age group mortality was $9.2 \%$ with EuroSCORE 6.7 (Table 1 and 2). On the other side, none of prognostic model for predicting mortality in elderly intensive care patients can be currently considered sufficiently valid to be appropriate in our clinical practice (9) (Table 1).

Anesthesiological protocol was the same throughout an operative period. A cardiopulmonary bypass for elective cardiac surgery is instituted with linear flow about 2.5 $\mathrm{L} / \mathrm{min} / \mathrm{m} 2$ and myocardial protection was performed using cold blood cardioplegia solution. Patients in the age group of 75 years and above, had a greater in-hospital mortality $(9.2 \%)$ compared to the other two groups $(\mathrm{p}=0.051)$. Some studies show a different incidence of in-hospital mortality in octogenerians undergoing cardiac surgery (from $6.5 \%$ to $9.2 \%$ ) $(10,11)$. The oldest age group of patients was on mechanical ventilation for a longer period of time, but without significance in comparison to the other two groups. Prolonged mechanical ventilation is classified as postoperative ventilation continued for more than 24 hours $(12,13)$. In the same group, there was an increased incidence of perioperative myocardial infarction $(4.0 \%)$, low cardiac output $(2.9 \%)$, stroke $(3.2 \%)$ and acute kidney injury (1.7\%), but without significance. Baskett et al. (10) reports higher incidence of stroke $(4.7 \%)$ in octogenerians undergoing CABG compared to the age group of 75 years and above. Vives et al. (14) showed a greater incidence of AKI (defined as a rise in serum creatinine $>1 \mathrm{mg} / \mathrm{dl}$ above baseline) at $2.5 \%$ in patients after CABG and at $2.8 \%$ after valvular surgery compared to our patients with AKI at $1.5 \%$. Sepsis and multiple organ dysfunction syndrome, as a progressive organ dysfunction in an acutely ill patient, were more common in the oldest age group but without significance in comparison to the other age groups $(15,16)$. This group of patients had one day longer length of hospital stay (18.5 days) compared to the other two groups (Table 2). In another retrospective investigation, Kolh et al. (17) reported an incidence of hospital mortality at $13 \%$ in 182 consecutive eighty-year-old patients after cardiac surgery and their length of hospital stay were 18.8 days.

Prospective data on long-term outcome were obtained by telephone conversation with the patient or the nearest kin. Follow-up showed that besides the number of years of life after surgery per se, for the older patients, the quality of life is a second important parameter. There has been no doubt that elderly patients who undergo cardiac surgery have an improvement in their quality of life $(18,19)$. Our follow-up questionnaire had not included questions about symptoms following surgery and other questions about the quality of life, but included two observational periods and causes of death, whether they were of cardiac or noncardiac cause. Overall the patient response to the telephone interview was $40.6 \%$ and was significantly smaller in the oldest age group (29.7\%). The most common reason for not responding were a change in phone number or address. The total mortality rate of the 711 interviewed patients amounted to $4.1 \%$ after the 6 -month and $10.8 \%$ after the 3 -year period of discharge from the hospital. The most common cause of mortality was cardiac death after both observed periods, after 6 -months (in $68.9 \%$ of cases) and after 3 -years (in $49.3 \%$ of cases). Even though the greatest mortality after both the 6-month and 3-year periods of discharge from the hospital was in the oldest age group $(7.8 \%$ and $14.6 \%)$, there were no differences between the groups (Table 3). One retrospective study shows an incidence of long-term survival after three years in the octogenarians undergoing cardiac surgery at $79.1 \%$ (15). Previous reports had shown that in spite of a relatively higher morbidity and mortality when compared with younger patients, elderly patients have an acceptable operative risk, and the long-term results are pleasing $(20,21)$. The TIME study presented the greater improvement of quality of life in patients older than 75 who underwent CABG regardless of their greater perioperative risk, compared to those with non-surgical treatment (22).

Even though this study included a large number of patients, limitations of study contain the weakness, inherent to any retrospective study. The study covers an extended period of time which the perioperative management of cardiac surgical patients may have been in some measure changed. In the follow-up study, despite three telephone calls made to every patient, nevertheless there was a poor response rate from the patients to the interview. Furthermore, we did not analyze the actual survival rate after surgery or the quality of life of patients by a questionnaire after hospital discharge, which is something that could be included in a future study, with important implications on long-term outcome. At last, comparison to age-matched population of patients with the same cardiac abnormalities, who were eligible for surgery is a theoretical option, but it would be difficult to perform.

In conclusion, we have confirmed that despite a poor short and long-term outcome in patients aged 75 and over, all patients aged 65 years and above after elective cardiac surgery, have a satisfactory operative risk in our clinical setting.

\section{REFERENCES}

1. Croatian Bureau of Statistics. Census of population, households and dwellings 2011, population by sex and age. (SI-1468[1]. pdf on Internet). Zagreb: Croatia, [updated 17 December 2012; cited 12 July 2013] Available from: http://www.dzs.hr/default_e.htm

2. Croatian Bureau of Statistics. Statistical Yearbook of the Republic of Croatia 2017, (SLJH2017.pdf on Internet). Zagreb: Croatia, [cited 30 June 2017] /update. Available from: http://www.dzs.hr/Hrv_Eng/ljetopis/2017/sljh2017.pdf

3. Nejasmic I, Toskic A. Ageing of the population in Croatia - the current situation and perspectives. Hrv geogr glasnik. 2013;75:89110.

4. Shapira OM, Kelleher RM, Zelingher J, Whalen D, Fitzgerald C, Aldea GS, et al. Prognosis and quality of life after valve surgery in patients older than 75 years. Chest. 1997;112:885-94. 
5. Barisin S, Husedzinovic I, Bradic N, Tonkovic D, Barisin A. Estimation of a new prognostic scoring system in anesthesia: The Cardiac anesthesia risk evaluation score. Neurol Croat. 2003;52(Suppl 3):127-35.

6. Michel P, Roques F, Nashef S. Logistic or additive EuroSCORE for high-risk patients? Eur J Cardiothorac Surg. 2003;23:684-7.

7. Gogbashian A, Sedrakyan A, Treasure T. EuroSCORE: a systematic review of international performance. Eur J Cardiothorac Surg. 2004;25:695-700.

8. Sündermann S, Dademasch A, Praetorius J, Kempfert J, Dewey T, Falk V, et al. Comprehensive assessment of frailty for elderly highpatients undergoing cardiac surgery. Eur J Cardiothorac Surg. 2011;39:33-7.

9. Minne L, Ludikhuize J, de Jonge E, de Rooij S, Abu-Hanna A. Prognostic models for predicting mortality in elderly ICU patients: a systematic review. Intensive Care Med. 2011;37:1258-68.

10. Baskett R, Buth K, Ghali W, Norris C, Maas T, Maitland A, et al. Outcomes in octogenarians undergoing coronary bypass grafting. CMAJ 2005;172:1183-6.

11. Bhamidipati CM, LaPar DJ, Fonner E Jr, Kern JA, Kron IL, Ailawadi G. Outcomes and cost of cardiac surgery in octogenarians is related to type of operation: a multiinstitutional analysis. Ann Thorac Surg. 2011;91:499-505.

12. Trouillet JL, Combes A, Vaissier E, Luyt CE, Ouattara A, Pavie A, et al. Prolonged mechanical ventilation after cardiac surgery: outcome and predictors. J Thorac Cardiovasc Surg. 2009;138:948-53.

13. Shirzad M, Karimi A, Ahmadi A, Marzban M, Tazik M, Aramin H. Predictors and early outcome of prolonged mechanical ventilation in contemporary heart valve surgery. Monaldi Arch Chest Dis. 2010;74:22-7.

14. Vives M, Wijeysundera D, Marczin N, Monedero P, Rao V. Cardiac surgery-associated acute kidney injury. Interact Cardiovasc Thorac Surg. 2014;18:637-45.

15. Rhodes A, Evans L, Alhazzani W, Levy MM, Antonelli M, Ferrer R et al. Surviving sepsis campaign: International guidelines for management of sepsis and septic shock: 2016. Crit Care Med 2017; 45:486-552.

16. Marshall JC, Cook DJ, Christou NV, Bernard GR, Sprung CL, Sibbald WJ. Multiple organ dysfunction score: a reliable descriptor of a complex clinical outcome. Crit Care Med 1995;23:1638-52.

17. Kohl P, Kerzmann A, Lahaye L, Gerard P, Limet R. Cardiac surgery in octogenarians: perio-operative and long-term results. Eur Heart J 2001;22:1235-43.

18. Mittermair RP, Muller LC. Quality of life after cardiac surgery in the elderly. J Cardiovasc Surg 2002;43:43-7.

19. Abah U, Dunne M, Cook A, Hoole S, Brayne C, Vale L, et al. Does quality of life improve in octogenarians following cardiac surgery? A systematic review. BMJ Open. 2015;5(4):e006904.

20. Fruitman SD, MacDougall CE, Ross DB. Cardiac surgery in octogenarians: can elderly patients benefit? Quality of life after cardiac surgery. Ann Thorac Surg 1999;68:2129-35.

21.Zaidi AM, Fitzpatrick AP, Keenan DM, Odom NJ, Grotte GJ. Good outcomes from cardiac surgery in the over 70s. Heart 1999;82:134-7.

22. TIME Investigators. Trial of invasive versus medical therapy in elderly patients with chronic symptomatic coronary-artery disease (TIME): a randomised trial. Lancet 2001;358:951-7. 